\title{
Crustal analysis of maud rise from combined satellite and near-surface magnetic survey data
}

\author{
Hyung Rae Kim ${ }^{1}$, Ralph R. B. von Frese ${ }^{2}$, Alexander V. Golynsky ${ }^{3}$, Patrick T. Taylor ${ }^{4}$, and Jeong Woo Kim ${ }^{5}$ \\ ${ }^{1}$ Goddard Earth Science and Technology, University of Maryland, Baltimore County at Planetary Geodynamics Lab, \\ NASA/GSFC, Greenbelt, Maryland, USA \\ ${ }^{2}$ Department of Geological Sciences, The Ohio State University, Columbus, Ohio, USA \\ ${ }^{3}$ VNII Okeangeologia, St. Petersburg, Russia \\ ${ }^{4}$ Code 698, Planetary Geodynamics Lab, NASA/GSFC, Greenbelt, Maryland, USA \\ ${ }^{5}$ Department of Geoinformatic Engineering, Sejong University, Seoul, South Korea
}

(Received February 20, 2004; Revised April 12, 2005; Accepted May 1, 2005)

\begin{abstract}
We produced a crustal magnetization model for the Maud Rise in the southwest Indian Ocean off the coast of East Antarctica using magnetic observations from the Ørsted satellite and near-surface surveys complied by the Antarctic Digital Magnetic Anomaly Project (ADMAP). Joint inversion of the two anomaly fields suggests that the magnetic effects due to crustal thickness variations and remanence involving the normal polarity Cretaceous Quiet Zone $(\mathrm{KQZ})$ dominate at satellite altitude $(\sim 700 \mathrm{~km})$. The crustal thickness effects were modeled in the Ørsted data using crustal thickness variations derived from satellite altitude gravity data. Modeling of the residual Ørsted and near-surface magnetic anomalies supports extending the KQZ eastwards to the Astrid Ridge. The remaining near-surface anomalies involve crustal features with relatively high frequency effects that are strongly attenuated at satellite altitudes. The crustal modeling can be extended by the satellite magnetic anomalies across the Indian Ocean Ridge for insight on the crustal properties of the conjugate Agulhas Plateau. The modeling supports the Jurassic reconstruction of Gondwana when the African Limpopo-Zambezi and East Antarctic Princess Astrid coasts were connected as part of a relatively demagnetized crustal block.
\end{abstract}

Key words: Maud Rise, Magnetic anomaly, Antarctic geology, Aeromagnetic data, Orsted, tectonic reconstructions.

\section{Introduction}

Continents are composed of crustal blocks with different ages, compositions, tectonic histories, and contrasting magnetic properties dominated mostly by induction (Hinze and Zietz, 1985) with effects that can be detected at satellite altitude (e.g., von Frese et al., 1986; Taylor and Frawley, 1987; Ravat et al., 1992). Oceanic crust, on the other hand, is compositionally more homogeneous, but predominantly magnetized by the remanent effects of seafloor spreading. For the most part, the alternating striped seafloor spreading anomalies are narrow so that their effects are generally canceled and strongly attenuated at satellite altitude (LaBrecque and Raymond, 1985; Hinze et al., 1991; Toft and Arkani-Hamed, 1993). There are exceptions, however, such as Cretaceous Quiet Zone (KQZ) anomalies that were created during a long $35 \mathrm{Ma}$ span of normal geomagnetic polarity (Fullerton et al., 1994). These anomalies are typically visible at the satellite altitude and provide important constraints on the regional remanent magnetization properties of the oceanic crust (LaBrecque and Raymond, 1985; Harrison et al., 1986; Thomas, 1987; Arkani-Hamed, 1988; Fullerton et al., 1994). Satellite magnetic anomalies have also been observed over oceanic plateaux, rises and subduc-

Copyright (c) The Society of Geomagnetism and Earth, Planetary and Space Sciences (SGEPSS); The Seismological Society of Japan; The Volcanological Society of Japan; The Geodetic Society of Japan; The Japanese Society for Planetary Sciences; TERRAPUB tions zones that are generally interpreted for induced magnetization effects (Frey, 1985; Bradley and Frey, 1988; Toft and Arkani-Hamed, 1992). These anomalies commonly correlate positively to bathymetric features with anomaly maxima over plateaux and rises, and minima over the basins (Frey, 1982; Hinze et al., 1991).

One of the most prominent satellite anomalies of the Antarctic is associated with the KQZ that includes the Maud Rise. As shown in Fig. 1(A), Maud Rise is centered at the NE trending bathymetric maximum off the southwest Indian Ocean coast of East Antarctica between the Weddell Sea Embayment (WSE) and the Astrid Ridge (AR). Maud Rise (MR) and the Agulhas Plateau (AP) probably separated during a ridge jump at $93 \mathrm{Ma}$ (Martin and Hartnady, 1986; Fullerton et al., 1994). These features form part of the KQZ that extends across the southwest Indian Ocean from southern Africa to the northeastern Weddell Sea Embayment (Purucker et al., 1998, 1999; Marks and Tikku, 2001).

Magsat anomalies for this KQZ have been modeled mostly for their remanent properties with relatively limited consideration of the inductive components due to crustal structural and compositional variations (e.g., Fullerton et al., 1994). In particular, regional inductive magnetic effects due to crustal thickness variations such as between oceans and continents have been difficult to resolve in satellite magnetic observations at both regional (Harrison et al., 


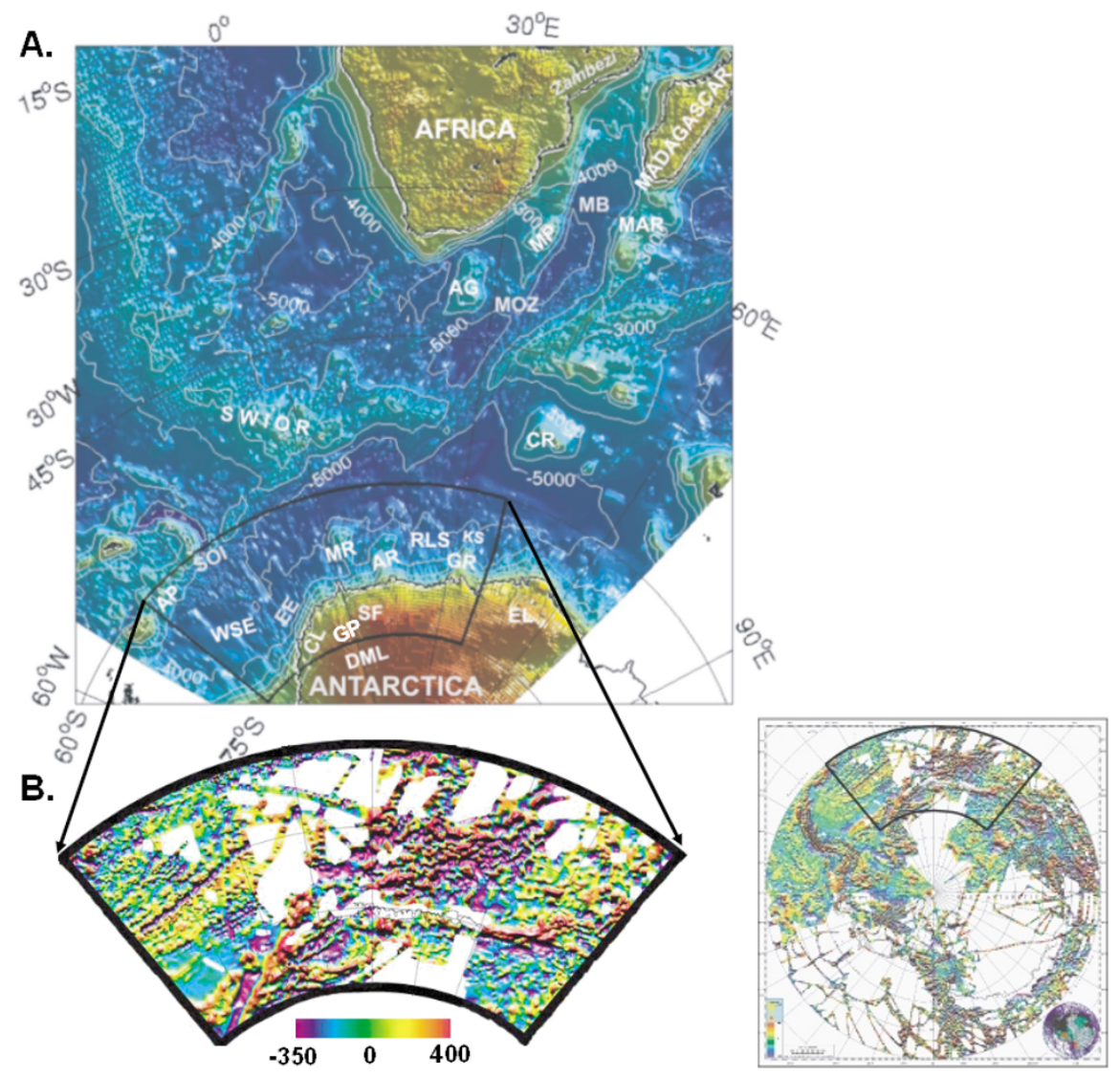

Fig. 1. A. NOAA/NGDC 5 arc minute digital terrain model. B. ADMAP anomalies in $n T$ over study area. The right-hand side of the figure: The ADMP compilation of Antarctic (Golynsky et al., 2001); thick black border delineates the study area. Annotated features include AG (Agulhas Plateau); AP (Antarctic Peninsula); AR (Astrid Ridge); CL (Coats Land); CR (Conrad Rise); DML (Dronning Maud Land); EE (Explora Escarpment); EL (Enderby Land); GP (Grunehogna Province); GR (Gunnerus Ridge); KS (Kainanmaru Seamount); MAR (Madagascar Ridge); MB (Mozambique Basin); MOZ (Mozambique Ridge); MP (Mozambique Plateau); MR (Maud Rise); RLS (Riiser-Larsen Sea); SF (HU Sverdrupfjella); SOI (South Oakney Islands); SWIOR (Southwest Indian Ocean Ridge); and WSE (Weddell Sea Embayment).

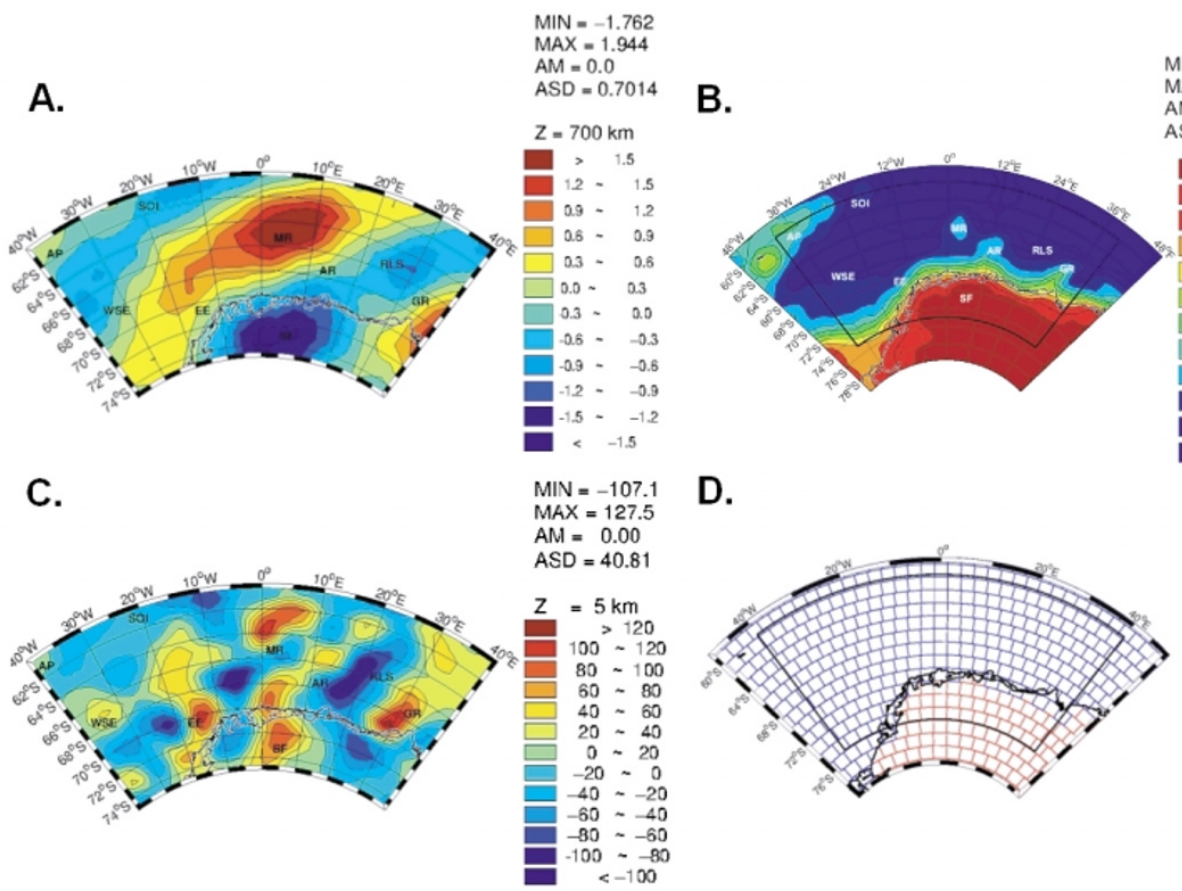

Fig. 2. A. Ørsted Maud Rise magnetic anomalies (nT) at the altitude (Z) of $700 \mathrm{~km}$. The listed map attributes include the minimum (MIN), maximum (MAX), and mean (AM) amplitudes, as well as the standard deviation (ASD) of the amplitudes. B. Gravity crustal thickness variation estimates in $\mathrm{km}$. C. ADMAP Maud Rise magnetic anomalies (nT) at $5 \mathrm{~km}$ low-pass filtered for $>500 \mathrm{~km}$ wavelengths. D. Distribution of spherical prisms for 3-D magnetic modeling of the crust. 
1986; Bradley and Frey, 1988; Hinze et al., 1991) and global (Cain et al., 1984; Arkani-Hamed and Strangway, 1985) scales. These long wavelength effects that should be particularly evident in the vicinity of Maud Rise were lacking because they were erroneously incorporated into the core field estimates that were removed in the production of the anomalies (e.g., Meyer et al., 1985; Counil et al., 1991; Hayling, 1991; von Frese et al., 1999a, 2003).

The Magsat mission was launched in Nov. 1979 and measured magnetic observations to an accuracy of roughly 3$6 \mathrm{nT}$ at altitudes of about $350-450 \mathrm{~km}$ (e.g., Langel and Hinze, 1998). However, this 6-month mission operated during Austral summer and fall periods when south polar external field activity was maximum. The spatially and temporally dynamic effects of the auroral external fields are at least two orders of magnitude larger than the static lithospheric anomalies. Thus, despite the development of extensive statistical procedures to reduce the Magsat observations for non-lithospheric noise (Alsdorf et al., 1994; von Frese et al., 2003), the veracity of the lithospheric components in the Antarctic Magsat anomalies remained doubtful until new satellite observations from the 1999 launch of the Ørsted mission provided verification (Kim et al., 2002).

Unlike Magsat, Ørsted operates above the ionosphere at altitudes of about $650-750 \mathrm{~km}$ obtaining magnetic observations with roughly 0.3 -nT measurement accuracy and much lower ionospheric noise levels (Neubert et al., 2001). However, despite the higher relative orbital altitudes, Ørsted lithospheric anomalies are eminently more suitable for comparing with Antarctic near-surface magnetic survey data than Magsat anomalies because of the order-ofmagnitude improvement in measurement accuracy (Kim et al., 2004).

In testing the veracity of Magsat's satellite lithospheric anomaly estimates of the Antarctic, we processed Austral winter magnetic observations from the Ørsted mission for a comprehensive set of lithospheric anomalies that includes both standard degree 13 and higher estimates (Kim et al., 2002), as well as the lower degree components from thickness variations of the crust (Kim, 2002; von Frese et al., 2003). We obtained the lower degree anomaly components using the pseudo magnetic effects of Antarctic crustal thickness estimates from the spectral correlation analysis of freeair and computed terrain gravity effects at satellite altitude (von Frese et al., 1999a). Figure 2(A) shows the comprehensive lithospheric Ørsted magnetic anomalies for the Maud Rise region. In the present study, we combine these Ørsted anomalies with regional components of the nearsurface magnetic anomalies in Fig. 1(B) (Golynsky et al., 2001) from the Antarctic Digital Magnetic Anomaly Project (ADMAP) to develop a crustal model of the regional induced and remanent magnetization properties for the Maud Rise. We also investigate the role of the satellite magnetic anomalies to extrapolate these results to the crustal properties of the conjugate Agulhas Plateau, as well as to test the Jurassic fit of the South African coast to East Antarctica.

\section{Magnetic Modeling of the Maud Rise Crust}

The Ørsted anomalies (Fig. 2(A)) in this area appear to reflect mostly the superposed effects of the continent-ocean crustal edge and the crustal remanence of the KQZ. For modeling the magnetizations, we used the crustal thickness variations in Fig. 2(B) derived by von Frese et al. (1999a). These variations were estimated from the inversion of isostatically adjusted complete Bouguer gravity anomalies that were defined at $150 \mathrm{~km}$ altitude by subtracting the gravity effects of the terrain from the terrain-correlated freeair anomalies assuming these free-air anomalies reflected the effects of uncompensated crustal terrain. Figure 2(D) gives the distribution of crustal prisms that we used to represent the crustal thickness variations of Fig. 2(B). We modeled these $150 \mathrm{~km}$-wide crustal prisms for their magnetic effects in spherical Earth coordinates by Gauss-Legendre quadrature integration (von Frese et al., 1981b). Our magnetic crustal thickness modeling assumed the mantle is relatively non-magnetic (Wasilewski et al., 1979; Wasilewski and Mayhew, 1992) and the Curie isotherm is everywhere deeper than the Moho.

For modeling the crustal prisms of the continent, we used an average susceptibility of 0.01 SI that is consistent with the broad range of susceptibilities measured for continental granite (e.g., Clark and Emerson, 1991). For the oceanic crust, we adopted an average susceptibility of 0.03 SI (e.g., Thomas, 1987) that reflects the induced magnetic characteristics of oceanic layer 2 (e.g., Roeser et al., 1996). This value compares well with the 0.033-0.038 SI range of susceptibilities inferred by Fullerton et al. (1994) for the induced and viscous crustal remanent magnetizations of Maud Rise based on geochemical data from alkali basalt at Site $690\left(65.1^{\circ} \mathrm{S}, 1.1^{\circ} \mathrm{E}\right)$ of the Ocean Drilling Program (Schandl et al., 1990). Combining this simple model of crustal susceptibilities with the Ørsted99 core field (Olsen $e t$ al., 2000) updated to 1999.0 and the crustal thickness variations (Fig. 2(B)) yields the magnetic anomaly estimates in Fig. 3(A) at $700 \mathrm{~km}$ altitude. The correlation coefficient is 0.4 between these anomaly predictions and the Ørsted lithospheric anomalies (Fig. 2(A)) and hence supports the notion that the degree $13+$ components of the Ørsted magnetic data may contain substantial crustal thickness effects. However, the Ørsted anomalies reflect other crustal magnetization effects than just the effects of the crustal thickness variations. These other effects may be brought out by subtracting the crustal thickness magnetic effects (Fig. 3(A)) from the Ørsted anomalies (Fig. 2(A)) for the residual anomalies given in Fig. 3(B).

To model the remanent effects for the Ørsted anomalies of the KQZ in Fig. 3(B), we must consider the differences in the magnetization of the crust at the time of its formation and its present day magnetization by the core field. For our analysis we used the paleoinclinations and declinations used by Dyment and Arkani-Hamed (1998) for the KQZ between the 83 and $118 \mathrm{Ma}$ isochrons (Harland et al., 1989), as well as a paleointensity of $42,200 \mathrm{nT}$, which is the mean core field intensity of the region. With the remanent magnetization directions for the oceanic crustal prisms, we obtained by least squares matrix inversion a crustal magnetization model with a calculated anomaly field that matches the residual Ørsted anomalies (Fig. 3(B)) with negligible error.

Summing the induced and remanent anomaly predictions in Figs. 3(A) and 3(B), respectively, yields the to- 


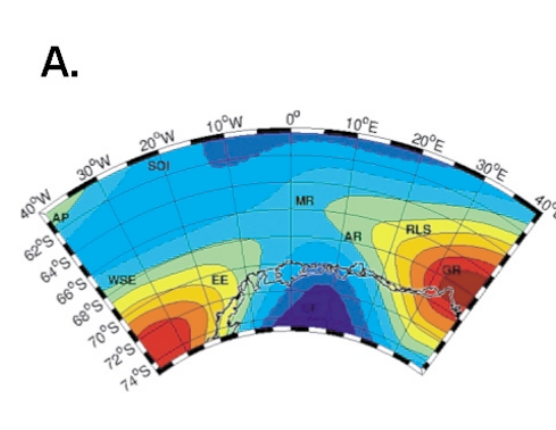

MIN $=-1.858$
MAX $=2.222$

$\mathrm{MAX}=2.222$
$\mathrm{AM}=0.0$

B. $\mathrm{ASD}=0.8848$
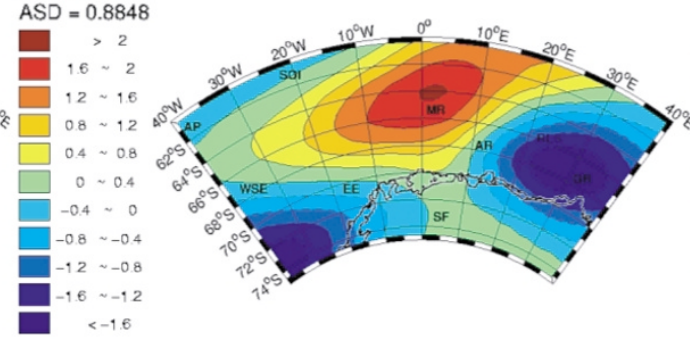

$\mathrm{MIN}=-1.966$

$\mathrm{MAX}=2.034$

$\mathrm{AM}=0.0$

ASD $=0.9378$

c.

$\mathrm{MIN}=-104.8$

$M A X=93.75$

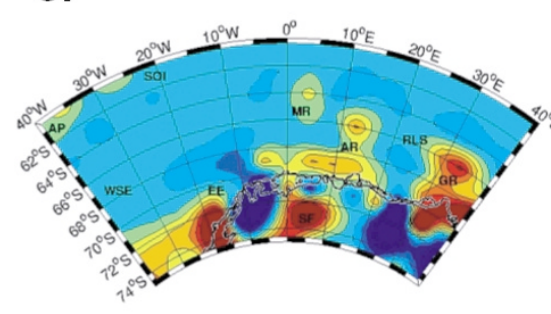

$\mathrm{AM}=0.0$

$\begin{aligned} \mathrm{ASD}= & 24.08 \\ & >50\end{aligned}$

D.

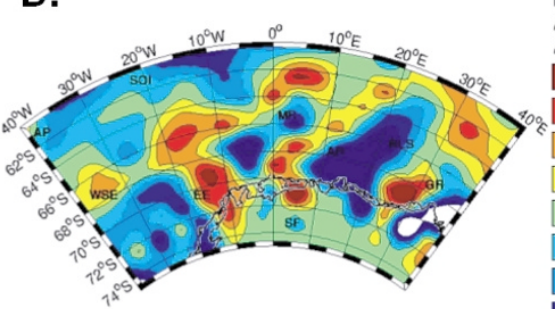

[ $>2$

$16 \sim 2$
$12 \sim 1.6$

$0.8 \sim 12$
$0.4 \sim 0.8$

प $0 \sim 0.4$

$-0.4 \sim 0$

$\begin{array}{lll}-0.8 & -0.4 \\ -12 & \sim-0.8\end{array}$

-1.6 $\sim-1$

$<-1.6$

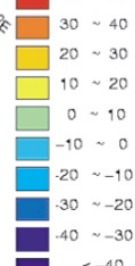

$<-40$

Fig. 3. A. Modeled crustal induced magnetic anomalies (nT) at $700 \mathrm{~km}$. B. Residual Ørsted crustal magnetic anomalies (nT) at $700 \mathrm{~km}$. C. Modeled near-surface crustal induced magnetic anomalies (nT) at $5 \mathrm{~km}$. D. Modeled near-surface crustal remanent magnetic anomalies (nT) at $5 \mathrm{~km}$.

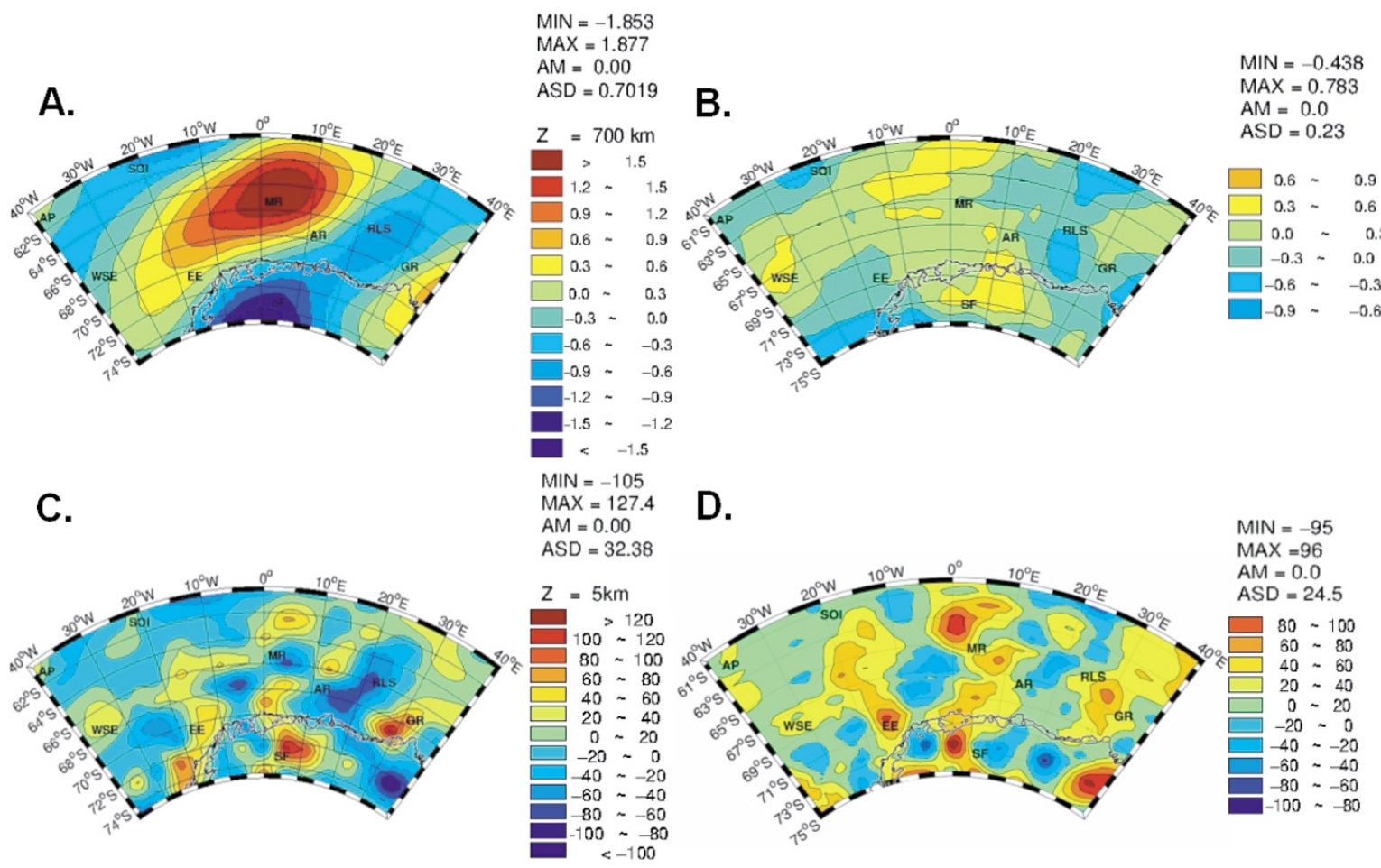

Fig. 4. Integrated crustal magnetic anomaly predictions (nT) at $700 \mathrm{~km}(\mathrm{~A})$ and modeling errors (B). Integrated near-surface crustal magnetic anomaly predictions (nT) at $5 \mathrm{~km}(\mathrm{C})$ and modeling errors (D).

tal anomaly estimates in Fig. 4(A) that match the Ørsted lies. anomalies in Fig. 2(A) to within the small anomaly residuals shown in Fig. 4(B). The good agreement between Figs. 2(A) and 4(A) suggests that the induced effects from the crustal thickness variations and the regional remanent effects of the KQZ dominate the Ørsted magnetic anoma-
Next, we updated the Ørsted magnetization model to also accommodate the near-surface ADMAP magnetic anomalies (Golynsky et al., 2001) low-pass filtered for $500 \mathrm{~km}$ and longer wavelengths given in Fig. 2(C). For this analysis, we neglected the shorter wavelength near-surface anomalies 
that have only marginal effects at satellite altitudes (e.g., Pilkington and Hildebrand, 2000; Ravat et al., 2002).

We computed near-surface anomaly residuals by subtracting the effects of the magnetization model derived above for Ørsted data from the regional ADMAP anomalies. Specifically, we determined another set of volume magnetic susceptibilities for the crustal prisms in Fig. 2(D) from the joint inversion (Ravat et al., 1998) of these ADMAP near-surface residuals and the Ørsted residuals in Fig. 4(B). Here, we applied the same remanent and induced polarization attributes to the oceanic and continental crustal prisms that we had used to model the Ørsted magnetic anomaly components in Figs. 3(A) and 3(B).

By joint inversion, we obtained susceptibility contrasts (X) using the damped least squares solution (e.g., von Frese et al., 1988) given by

$$
\mathbf{X}=\left[\mathbf{A}^{T}+(E V) \mathbf{I}\right]-1 \mathbf{A}^{T} \mathbf{B}
$$

where $\mathbf{A}$ is the design matrix of coefficients describing the prism polarizations and displacement vectors between the crustal prisms and near-surface and satellite altitude residual anomalies, $\mathbf{A}^{T}$ is the transpose of $\mathbf{A}, \mathbf{I}$ is the identity matrix, $\mathbf{B}$ is the observation vector of satellite and the near-surface residual anomalies, and the scalar $E V$ is the error variance. We used trade-off diagrams to establish the 'optimal' $E V=10^{4}$ for a solution $(\mathbf{X})$ that modeled both sets of anomaly residuals with negligible errors and also yielded geologically reasonable magnetization variations for the continental and the oceanic crustal prisms.

The comprehensive crustal magnetization model for the Maud Rise in Fig. 5(A) obtained by this optimal EV predicts magnetic effects that correlate at 0.94 and 0.95 with the residual Ørsted and low-pass filtered near-surface ADMAP anomalies, respectively. These magnetizations represent the integration of the induced and remanent magnetizations in Figs. 5(B) and 5(C), respectively and are in good agreement with the crustal magnetic properties inferred from other magnetic studies (Ghidella et al., 1991; Fullerton et al., 1994; Purucker et al., 1999). The remanent magnetizations in Fig. 5(C) were obtained by superposition of the remanent magnetizations from the joint inversion of the Ørsted and low-pass filtered near-surface ADMAP anomalies, while the induced magnetizations in Fig. 5(B) were integrated from the induced magnetization models of these anomalies.

The combined inductive and remanent magnetizations in Fig. 5(A) yield the satellite and near-surface anomaly predictions in Figs. 4(A) and 4(C), respectively, with the respective modeling errors in Figs. 4(B) and 4(D). The comparatively weak residuals of Fig. 4(B) indicate that our crustal magnetization modeling for thickness variations and the KQZ mostly accounts for the magnetic anomalies at Ørsted altitudes. Accounting for the relatively more substantial near-surface residuals in Fig. 4(D), on the other hand, will require the consideration of additional crustal magnetic sources (e.g., petrological, thermal, etc.). However, for any perceived magnetic effect of a new crustal source in Figs. 4(B) and (D), we can clearly obtain the corresponding magnetization contrast by joint inversion to update the magnetization model in Fig. 5(A).
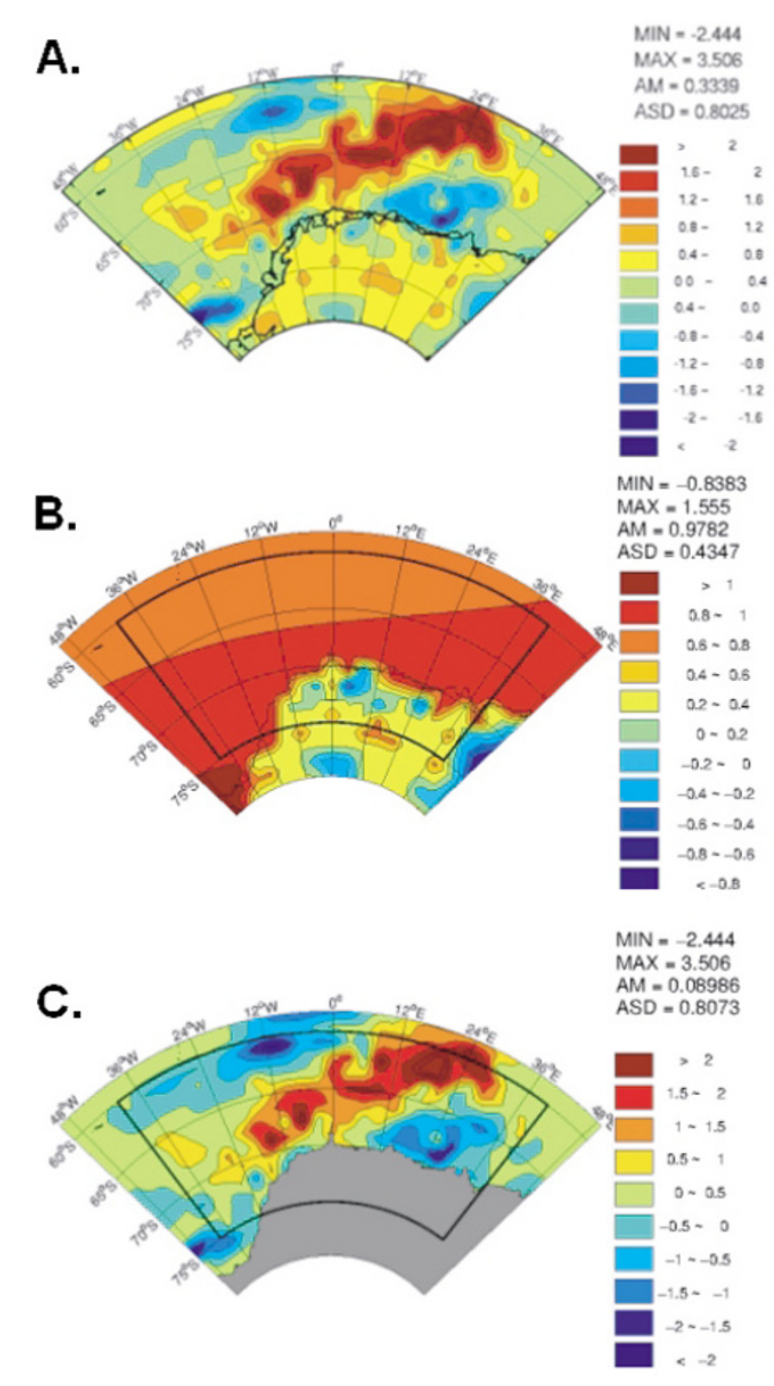

Fig. 5. A. Comprehensive crustal magnetization model $(\mathrm{A} / \mathrm{m})$ for the Maud Rise derived from the superposition of induced (B) and remanent (C) magnetizations.

\section{Regional Geology and Magnetization Varia- tions}

The induced and remanent magnetization contrasts in Figs. 5(B) and 5(C), respectively, exhibit considerable spatial variability that is common for the oceanic crust even at scales as small as a few kilometers (e.g. Smith, 1990). The most prominent positive magnetizations clearly involve the KQZ where we obtained a maximum remanent value of 2.1 A/m over the Maud Rise in Fig. 5(C). Our magnetizations for the Maud Rise are roughly $15 \%$ to nearly $70 \%$ lower than the respective values Ghidella et al. (1991) and Fullerton et al. (1994) obtained from analyses of the region's excessively noisy Magsat anomalies.

Our results suggest eastward extensions of the KQZ beyond the boundary inferred from the sea floor ages (e.g., Mueller et al., 1997; Dyment and Arkani-Hamed, 1998). These extensions reflect the contributions of the nearsurface anomalies in the joint inversion for magnetization models. Extensive oceanic regions of negatively contrasting magnetizations border the KQZ that include the RiiserLarsen Sea (RLS) to the east and Weddell Sea Embayment 

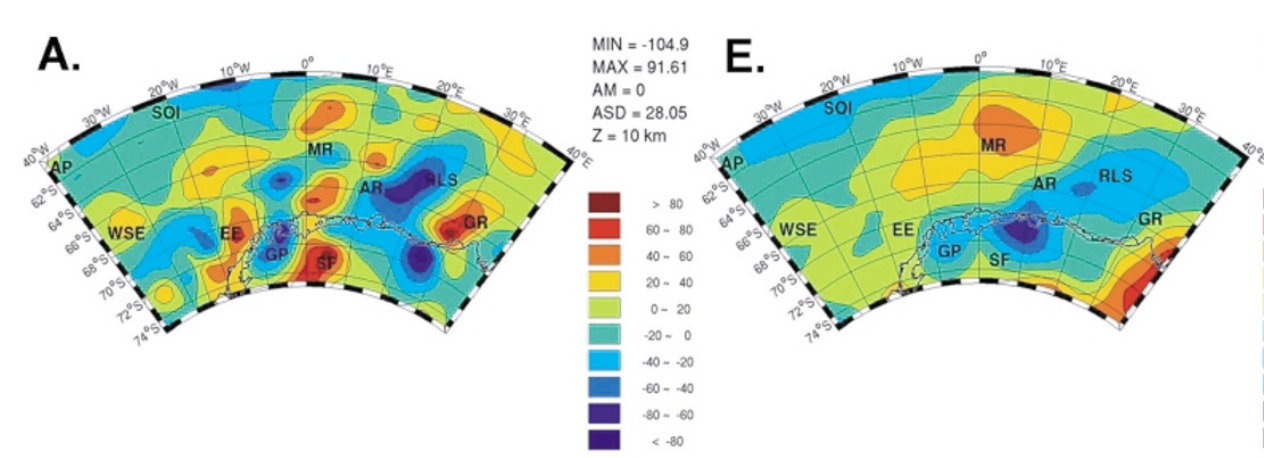

B.

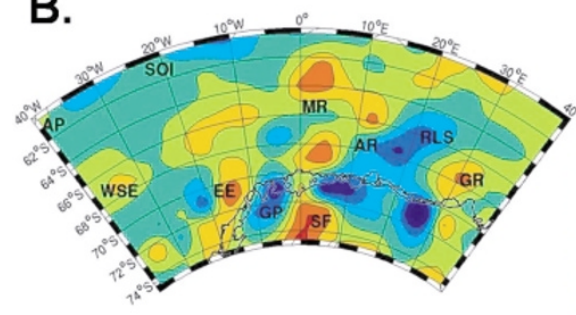

C.

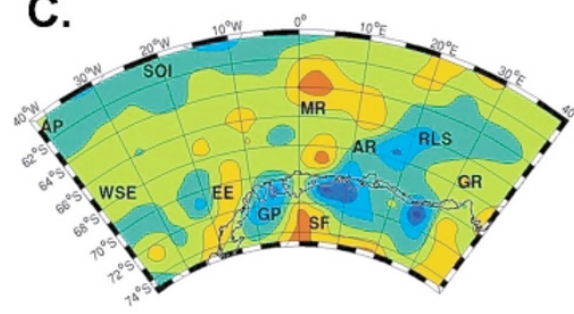

MIN $=-117.5$ $\mathrm{MAX}=65.34$ $A M=0$ $\mathrm{ASD}=23.61$ $Z=25 \mathrm{~km}$ $\mathrm{Z}=25 \mathrm{k}$

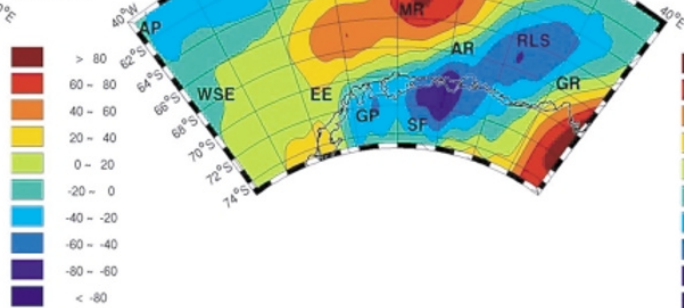

$F$.
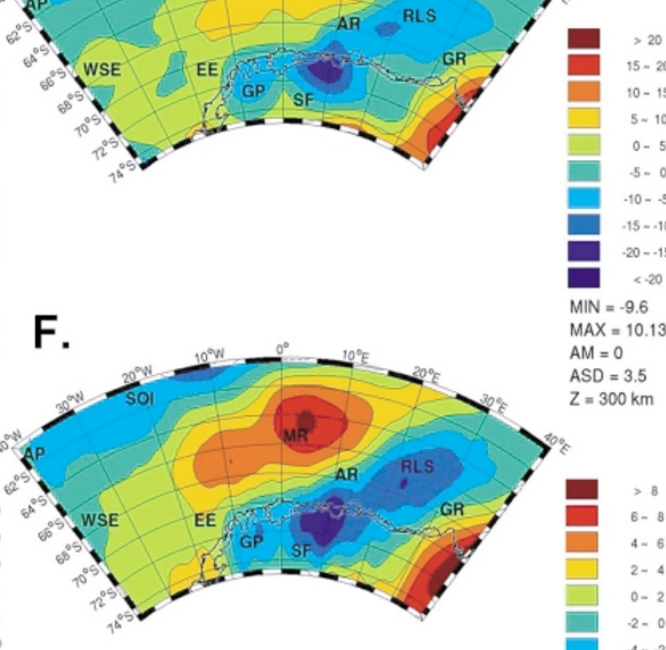
MIN $=-9.6$ MAX $=10.13$ $A M=0$ $\mathrm{ASD}=3.5$
$\mathrm{Z}=300 \mathrm{~km}$

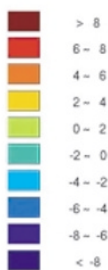

$\operatorname{MIN}=-68.54$ MAX
AM $=0$
5 $A M=0$ ASD $=17.69$

\section{G.}

MIN $=-5.019$ G. $\mathrm{Z}=400 \mathrm{~km}$

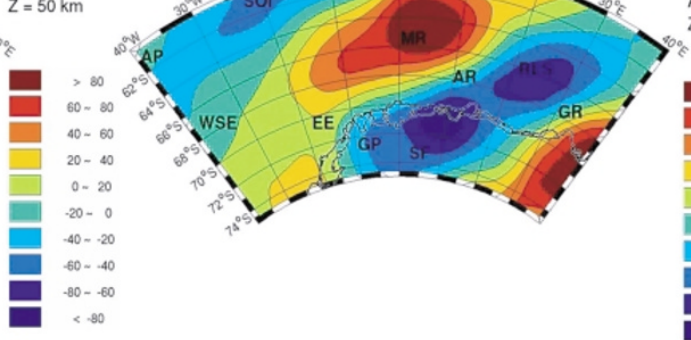

.

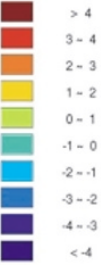

\section{D.}

MIN $=-42.33$ MAX $=38.93$ $A M=0$

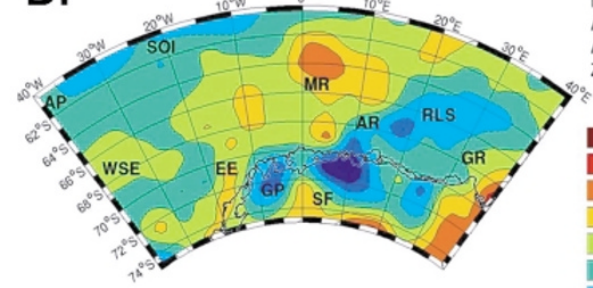
ASD $=11.65$
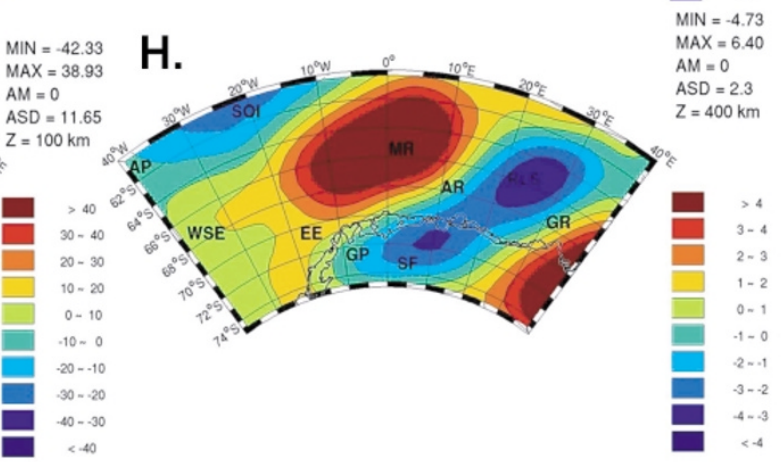

Fig. 6. Magnetic anomaly predictions in nT from the comprehensive crustal magnetization model (Fig. 5.A) at altitudes (Z) from 10 (A) to $400 \mathrm{~km}$ (G) where Magsat anomaly estimates $(\mathrm{H})$ are also presented for comparison.

(WSE) on the west. The paleoinclinations lack magnetic reversals to help account for these negative contrasts (Dyment and Arkani-Hamed, 1998). However, beneath these basins the crust is thinner than the Maud Rise crust that was thickened by hotspot activity away from the southwest Indian Ocean Ridge (Schandl et al., 1990). Hence, crustal thinning beneath the basins may contribute to these regionally negative contrasts in magnetization. Furthermore, sediment thicknesses up to $5 \mathrm{~km}$ have been reported for the RLS (Hinz and Krause, 1982; Leitchenkov et al., 1996; Ishihara et al., 1991), and the WSE (LaBrecque and Keller, 1982). Thus, additional magnetic property reductions may have resulted from hydrothermal demagnetization of the oceanic crust beneath the thermal blanketing sedimentary layers (Levi and Riddihough, 1986; Ghods, 1994).

The crustal magnetizations obtained by the joint inversion of magnetic anomalies independently observed at $5 \mathrm{~km}$ and $700 \mathrm{~km}$ altitudes can be analyzed for anomaly predictions at the intervening altitudes for additional perspectives on the crustal geology (von Frese et al., 1999b). Accordingly, we evaluated our magnetization models for 7 slices of the geomagnetic anomaly field over altitudes ranging from $10 \mathrm{~km}$ to $400 \mathrm{~km}$ as shown in Fig. 6. These perspectives provide insight on how the 5 or 6 satellite altitude anoma- 

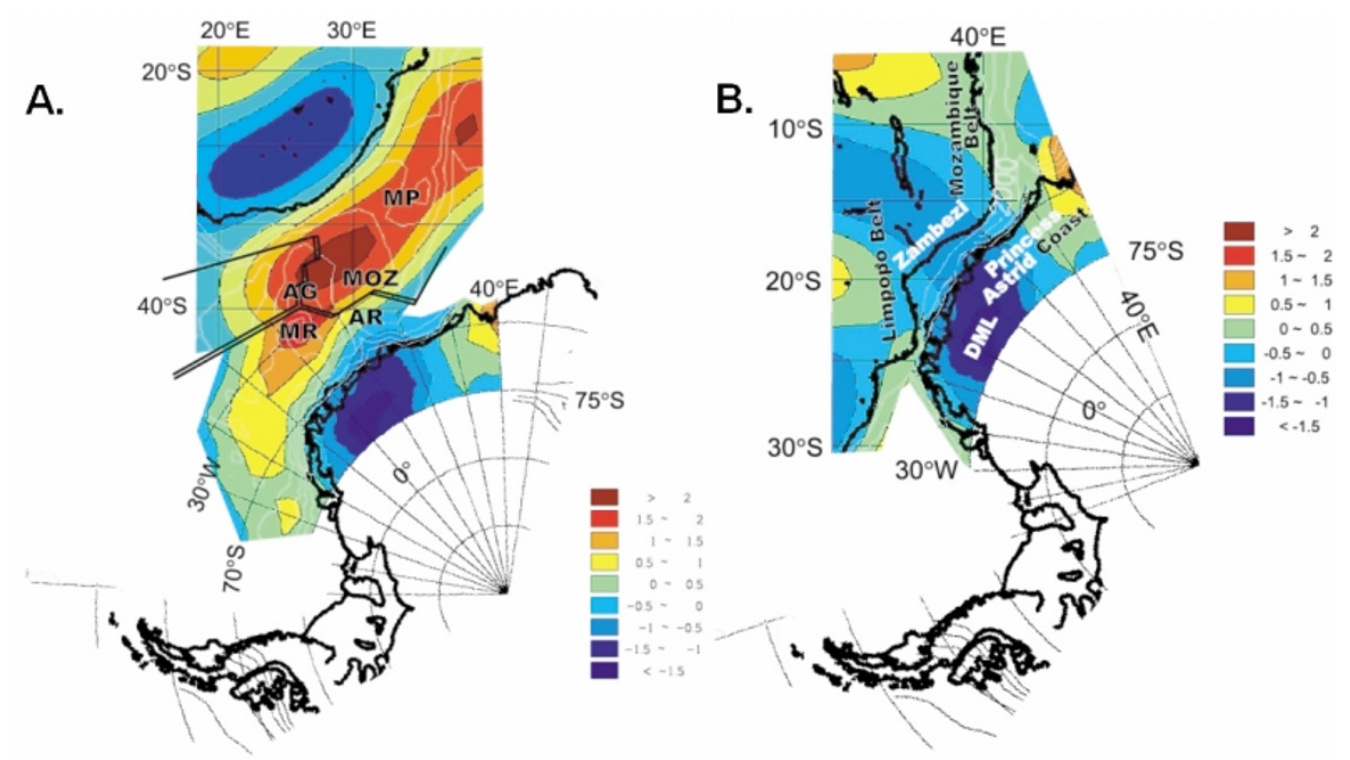

Fig. 7. Tectonic reconstructions of the Southeast Indian Ocean from satellite magnetic anomalies (nT) of the A) Cretaceous ( 93 Ma) and B) Jurassic $(\sim 150 \mathrm{Ma})$ periods.

lies break down with decreasing altitude into a complex multitude of anomalies at the near-surface. Alternatively, we can obtain insight on anomaly interference effects with elevation by studying how the near-surface anomalies coalesce with increasing altitude into the longer wavelength of anomalies that are observed at satellite altitude.

\section{Crustal Magnetic Anomaly Perspectives with Altitude}

At the near-surface altitudes (Figs. 6(A)-(B)) the KQZ is predominantly characterized by linear maxima flanking relatively well defined interior minima. It is only at altitudes of about $100 \mathrm{~km}$ and greater (Figs. 6(D)-(G)) that the strong, regionally positive magnetic character of the KQZ becomes apparent. Similarly, the near-surface magnetic minima along the coast of East Antarctica coalesce at altitudes of $100 \mathrm{~km}$ and higher with the Riiser-Larsen Sea (RLS) minimum. The near-surface continental minima are broken up by the maximum over HU Sverdrupfjella (SF) that flanks the eastern Grunehogna Province (GP) margin (e.g., Golynsky et al., 2000). This anomaly has been used in Gondwana reconstructions and may be related to the midProterozoic-to-Precambrian Maudheim Province (e.g., Corner, 1994). At altitudes of nearly $200 \mathrm{~km}$ and higher, the SF anomaly dies out and appears to connect with a positive anomaly over western Enderby Land (EL) that may reflect an Archean shield or platform (Bormann et al., 1986). The EL anomaly is weakly expressed in the near-surface data, but becomes increasingly prominent with altitude.

Data errors greatly limit the utility of single surface anomaly continuations (e.g., von Frese et al., 2004). Thus, the anomaly behavior suggested by joint inversion cannot be deduced from the simple downward continuation of the satellite altitude data or the upward continuation of the nearsurface magnetic data. Analysis of the correlation coefficients between the observed anomalies in Figs. 2(A) and 2(C) and the anomaly predictions in Fig. 6 suggests that the satellite data pretty much dominate the predictions down to $200 \mathrm{~km}$ altitude, while the near-surface data dominate up to $25 \mathrm{~km}$ (Kim, 2002). The favorable comparison of the Magsat anomalies in Fig. 6(A)-(B) with the magnetization model predictions at $400 \mathrm{~km}$ altitude in Fig. 6(G) further supports the satellite altitude properties of the lithospheric anomalies. Over the intervening altitudes between roughly $25 \mathrm{~km}$ and $300 \mathrm{~km}$, the joint inversion predictions in Fig. 6 provide insight on how the boundary value anomalies (Fig. 2) may transition into each other that the simple continuation of each individual data set by itself cannot reveal.

Unfortunately, like any inversion, the results of our joint inversion are not unique, and hence do not obviate the need for additional surveys at altitudes in-between the altitudes of the bounding data sets. In general, considerable uncertainty remains concerning the magnetic properties of the crust in our application because it involves patches of nearsurface and satellite magnetic data with limited coverage and anomaly accuracies. These limitations generally conspire to yield an incomplete picture of the spectral properties of the crustal anomalies. Thus, to help mitigate these limitations, supplemental magnetic observations are needed from surveys at intervening altitudes by aircraft $(\leq 25 \mathrm{~km})$, balloons $(\leq 40 \mathrm{~km})$ and satellites $(\geq 150 \mathrm{~km})$. The geologic utility of combining ADMAP and satellite magnetic anomalies will also grow substantially as CHAMP magnetic observations improve the Magsat anomaly estimates in Fig. 6(H) due to their order-of-magnitude better measurement accuracy (Kim et al., 2004).

\section{Tectonic Implications}

Analyses of the sea floor magnetic anomalies suggest that the Maud Rise and Agulhas Plateau were conjugate features during the Cretaceous as rifting separated southern Africa from East Antarctica (e.g., Martin and Hartnady, 1986; Schandl et al., 1990; Antoine and Moyes, 1992; 
Fullerton et al., 1994). Initially, the Agulhas Plateau was considered foundered continental crust based on seafloor dredging results (Tucholke et al., 1981). However, this notion is being questioned by recent seismic data that suggest the plateau is predominantly oceanic crust (Gohl and Uenzelmann-Neben, 2001). The enhanced thickening of the crust for these conjugate features probably involves excessive volcanism related to hotspot activity during separation of the two blocks (Martin and Hartnady, 1986; Schandl et al., 1990). Hence, the regional magnetic anomalies for these two rises should share similar characteristics to reflect the common formation history of the underlying crustal components.

To test our Ørsted anomalies of the Maud Rise, we upward continued to $700 \mathrm{~km}$ the $1^{\circ}$ crustal anomaly estimates for the region of the Agulhas Plateau that were obtained at $400 \mathrm{~km}$ from a combined data set of POGO and Magsat magnetic observations (Arkani-Hamed et al., 1994). We fit these anomalies to an array of crustal dipoles using least squares matrix inversion to solve for the magnetizations of the dipoles (von Frese et al., 1981a; von Frese, 1998). We then evaluated our point dipole model at $700 \mathrm{~km}$ for anomaly estimates over the Agulhas Plateau region to compare with our Ørsted anomalies over the Maud Rise region. Figure 7(A) compares the two sets of satellite anomalies for the 93 Ma reconstruction of the tectonic plates from Martin and Hartnady (1986). The remarkable fit of the positive satellite magnetic anomalies in Fig. 7(B) suggests that the magnetic crustal model for the Maud Rise may be readily extended to the Agulhas Plateau. Indeed, the NE-extension of the prominent positive satellite magnetic anomaly suggests that the Maud Rise model of thickened oceanic crust remanently magnetized in the Cretaceous may also account for the magnetic effects of the Mozambique Plateau (MP).

Continental satellite magnetic anomalies along the coast lines may also test older plate reconstructions. For example, in Fig. 7(B). the remarkable match of the South African satellite magnetic minimum along the Zambezi coast with the Dronning Maud Land (DML) minimum of East Antarctica strongly favors the Jurassic plate reconstruction of Martin and Hartnady (1986) for these regions. Petrological and geochronological studies of the igneous and metamorphic rocks from both regions suggest that the Dronning Maud Land crust may be analogous to the southern Mozambique Belt of East Africa (Jacobs et al., 1998). The magnetic minima reflect regional reductions in crustal magnetizations due probably to thermotectonic activation in the late Precambrian (Bormann et al., 1986).

\section{Conclusions}

The magnetic anomaly signatures for Maud Rise and adjacent Antarctic areas are marked by prominent maxima due to thickened oceanic crust with a strong thermoremanent component that was acquired during the mid-Cretaceous. The inductive effects of continent-ocean thickness variations and the remanent effects of the NE-SW trending KQZ that is centered on Maud Rise mostly account for the satellite altitude magnetic anomalies. These effects must be analyzed separately, but the resulting induced and remanent magnetizations can be readily integrated to effectively model the high-precision Ørsted magnetic anomalies at 700 $\mathrm{km}$ altitude. Furthermore, this magnetization model can be adjusted by the joint inversion of the satellite altitude residual and near-surface magnetic anomalies for crustal magnetizations that simultaneously satisfy the observed anomaly fields at both altitudes. In addition, the model provides new insights on the behavior of crustal anomalies between airborne and satellite altitudes to enhance the geologic utility of these independently surveyed data. However, the anomaly predictions are not unique in any application because the inversion always involves a highly simplified mathematical model of reality and thus is always underdetermined. Hence, the predictions do not obviate the need for supplemental magnetic measurements, especially at the intervening altitudes that may be accessed by high-altitude aircraft, balloons, and space shuttle tethers, to better define the geologic relationships in near-surface and satellite altitude magnetic fields.

The satellite magnetic anomalies in the vicinity of the Maud Rise in the Antarctic, and the Agulhas Plateau region of southern Africa, are strongly correlated in plate tectonic reconstructions of Martin and Hartnady (1986) for the Cretaceous. Accordingly, the crustal magnetic properties that we inferred for the Maud Rise may well extend to the crust of the Agulhas and Mozambique Plateaux to account for their regional magnetic effects. Similarly, the correlation of satellite magnetic minima over Dronning Maud Land in East Antarctica and the Zambezi coast of southeastern Africa supports the plate tectonic fit of these regions in the Jurassic. The presently orbiting CHAMP satellite is collecting magnetic and gravity data that will provide the highest resolution anomaly fields mapped to date for the Antarctic. These results will soon be complemented by improved gravity data from the GRACE and GOCE missions for further insights on the Antarctic lithosphere.

Acknowledgments. Elements of this research were produced with support from NASA Cooperative Agreement NCC5-494, NASA reward NNG04GQ44G and NSF-OPP research grant 0338005, and The Ohio Supercomputer Center at The Ohio State University. We thank Dr. Fausto Ferraccioli and an anonymous referee for their review comments that significantly improved the manuscript.

\section{References}

Alsdorf, D. E., R. R. B von Frese, J. Arkani-Hamed, and H. C. Noltimier, Separation of lithospheric, external, and core components of the south polar geomagnetic field at satellite altitudes, J. Geophys. Res., 99, 46554667, 1994.

Antoine, L. A. G. and A. B. Moyes, The Agulhas Magsat anomaly: implications for continental break-tip of Gondwana, Tectonophysics, $\mathbf{2 1 2}$, 33-44, 1992.

Arkani-Hamed, J., Remanent magnetization of the oceanic upper mantle, Geophys. Res. Lett., 15, 48-51, 1988.

Arkani-Hamed, J. and D. W. Strangway, Intermediate scale magnetic anomalies of the Earth, Geophysics, 50, 2817-30, 1985.

Arkani-Hamed, J., R. A. Langel, and M. Purucker, Magnetic anomaly maps of Earth derived from POGO and Magsat data, J. Geophys. Res., 99, 24,075-24,090, 1994.

Bormann, P., P. Bankwitz, E. Bankwitz, V. Damm, E. Hurtig, H. Kompf, M. Menning, H.-J. Paech, U. Schofer, and W. Stackegrandt, Structure and development of the passive continental margin across the Princess Astrid coast, East Antarctica, J. Geodyn., 6, 347-373, 1986.

Bradley, L. M. and H. Frey, Constraints on the crustal nature and tectonic history of the Kerguelen Plateau from comparative magnetic modeling 
using Magsat data, Tectonophysics, 145, 243-251, 1988.

Cain, J. C., D. R. Schmitz, and L. Muth, Small-scale features in the Earth's magnetic field observed by Magsat, J. Geophys. Res., 89, 1070-1076, 1984.

Clark, D. A. and D. W. Emerson, Notes on rock magnetization characteristics in applied geophysical studies, Exploration Geophysics, 22, 547$555,1991$.

Corner, B., Geological evolution of western Dronning Maud Land within a Gondwana framework: geophysics subprogramme, Final Project Rept. SACAR, 1994

Counil, J.-L., Y. Cohen, and J. Achache, A global continent-ocean magnetization contrast: spherical harmonic analysis, Earth Planet. Sci. Lett., 103, 354-64, 1991.

Dyment, J. and J. Arkani-Hamed, Contribution of lithospheric remanent magnetization to satellite magnetic anomalies over the world's oceans, J. Geophys. Res., 103, 15423-15441, 1998.

Frey, H., Magsat scalar anomaly distribution: the global perspective, Geophys. Res. Lett., 9, 277-280, 1982.

Frey, H., Magsat and POGO anomalies over the Lord Howe Rise: Evidence against a simple continental crustal structure, J. Geophys. Res., 90, 2631-2639, 1985.

Fullerton, L. G., H. V. Frey, J. H. Roark, and H. H. Thomas, Contributions of Cretaceous Quiet Zone natural remanent magnetization to Magsat anomalies in the Southwest Indian Ocean, J. Geophys. Res., 99, 1192336, 1994.

Ghidella, M., C. Raymond, and J. LaBrecque, Verification of crustal sources for satellite elevation magnetic anomalies in West Antarctica and the Weddell Sea and their regional tectonic implications, in Geological Evolution of Antarctica, edited by M. Thomson, J. Crame, and J. Thomson, pp. 243-250, Cambridge University Press, 1991.

Ghods, A. Negative magnetic anomalies at satellite altitude over passive marginal basins, Master's thesis, McGill University, 1994.

Gohl, K. and G. Uenzelmann-Neben, The crustal role of the Agulhas Plateau, southwest Indian Ocean: evidence from seismic profiling, Geophys. J. Int., 144, 632-646, 2001.

Golynsky, A. V., G. E. Grikurov, and E. N. Kamenev, Geological significance of regional magnetic anomalies in Coats Land and western Dronning Maud Land, Polarforshung, 67, 91-99, 2000.

Golynsky, A. V., M. Chiappini, D. Damaske, C. Finn, F. Ferraccioli, J. Ferris, M. Ghidella, T. Ishihara, A. Johnson, H. R. Kim, L. Kovacs, J. LaBrecque, V. Masolov, Y. Nogi, M. Purucker, P. Taylor, and M. Torta, ADMAP - A digital magnetic anomaly map of the Antarctic. 1:10,000 scale map. edited by P. Morris and R. von Frese, BAS (Misc.) 10, Cambridge, British Antarctic Survey, 2001.

Harland, W. B., R. L. Armstrong, A. N. Cox, L. E. Craig, A. G. Smith, and D. G. Smith, A Geologic Time Scale, New York: Cambridge Univ. Press, 1989.

Harrison, C. G. A., H. M. Carle, and K. L. Hayling, Interpretation of satellite elevation magnetic anomalies, J. Geophys. Res., 91, 36333650, 1986.

Hayling, K. L., Magnetic anomalies at satellite altitude over continentocean boundaries, Tectonophysics, 192, 129-143, 1991.

Hinz, K. and W. Krause, The continental margin of Queen Maud Land, Antarctica: Seismic sequences, structural elements and geological development, Geol. Jahrbuch, E23, 17-41, 1982.

Hinze, W. J. and J. Zietz, The composite magnetic anomaly map of the conterminous United States, in The Utility of Regional Gravity and Magnetic Anomaly Maps, edited by W. J. Hinze, pp. 1-24, Tulsa: Society of Exploration Geophysicists, 1985.

Hinze, W. J., R. R. B. von Frese, and D. N. Ravat, Mean magnetic contrasts between oceans and continents, Tectonophysics, 192, 117-127, 1991.

Ishihara, T., G. L. Leitchenkov, A. V. Golynsky, S. Alyavdin, and P. E. O'Brien, Compilation of shipborne magnetic and gravity data images crustal structure of Prydz Bay (East Antarctica), Ann. di. Geofisica, 44, 229-248, 1991.

Jacobs, J., C. M. Fanning, F. Henjes-Kunst, M. Olesch, and H.-J. Paech, Continuation of the Mozambique Belt into East Antarctica: GrenvilleAge metamorphism and polyphase Pan-African high-grade events in central Dronning Maud Land, J. of Geology, 106, 385-406, 1998.

Kim, H. R., Antarctic lithospheric anomalies from Ørsted satellite and near-surface magnetic observations, Ph.D. Thesis, The Ohio State University, Columbus, 2002

Kim, H. R., R. R. B. von Frese, J. W. Kim, P. T. Taylor, M. E. Purucker, and T. Neubert, Ørsted verifies regional magnetic anomalies of the Antarctic lithosphere, Geophys. Res. Lett., 29, ORS 3-1 to 3-3, 2002.

Kim, H. R., R. R. B. von Frese, A. V. Golynsky, P. T. Taylor, and J. W.
Kim, Application of satellite magnetic observations for estimating nearsurface magnetic anomalies, Earth Planets Space, 52, 955-966, 2004.

LaBrecque, J. L. and M. Keller, A geophysical study of the Indo-Atlantic Basin, in Antarctic Sciences, edited by C. Craddock, Univ. of Wisconsin Press, 331-337, 1982.

LaBrecque, J. L. and C. A. Raymond, Sea spreading anomalies in the Magsat field of the North Atlantic, J. Geophys. Res., 90, 2549-2564, 1985.

Langel, R. A. and W. J. Hinze, The Magnetic Field of the Earth's Lithosphere: The Satellite Perspective, 429 pp., Cambridge Univ. Press, New York, 1998.

Leitchenkov, G. L., H. Miller, and E. N. Zatzepin, Structure and Mesozoic evolution of the eastern Weddell Sea, Antarctica: History of early Gondwana break-up, in Weddell Sea Tectonics and Gondwana Breakup, edited by B. C. Storey, E. C. King, and R. A. Rivermore, Volume 108, pp. 175-190, London: Geological Society, 1996.

Levi, S. and R. Riddihough, Why are marine magnetic anomalies suppressed over sedimented spreading centers?, Geology, 14, 651-654, 1986.

Marks, K. M. and A. A. Tikku, Cretaceous reconstructions of East Antarctica, Africa and Madagascar, Earth. Planet. Sci. Lett., 186, 479-495, 2001.

Martin, A. K. and C. J. H. Hartnady, Plate tectonic development of the South West Indian Ocean: A revised reconstruction of East Antarctica and Africa, J. Geophys. Res., 91, 4767-4786, 1986.

Meyer, J., J. H. Hufer, M. Siebert, and A. Hahn, On the identification of Magsat anomaly charts as crustal part of internal field, J. Geophys. Res., 90, 2537-2542, 1985

Mueller, R. D., W. R. Roest, J. Y. Royer, L. M. Gahagan, and J. G. Sclater, Digital isochrons of the world's ocean floor, J. Geophys. Res., 102(B2), 3211-3214, 1997.

Neubert, T., M. Mandea, G. Hulot, R. von Frese, F. Primdahl, J. L. Jørgensen, E. Friis-Christensen, P. Stauning, N. Olsen, and T. Risbo, Ørsted satellite captures high-precision geomagnetic field data, EOS (Am. Geophys. Union Trans.), 82, 81 and 86-88, 2001.

Olsen, N., T. Sabaka, and L. T. Clausen, Determination of the IGRF 2000, Earth Planets Space, 52, 1175-1182, 2000.

Pilkington, M. and A. R. Hildebrand, Three-dimensional magnetic imaging of the Chicxulub Crater, J. Geophys. Res., 105, 23,479-23,491, 2000.

Purucker, M. E., R. A. Langel, M. Rajaram, and C. Raymond, Global magnetization models with a priori information, J. Geophys. Res., 103, 2563-2584, 1998

Purucker, M. E., R. R. B. von Frese, and P. T. Taylor, Mapping and interpretation of satellite magnetic anomalies from POGO data over the Antarctic region, Ann. di. Geofisica, 42, 215-228, 1999.

Ravat, D., W. J. Hinze, and R. R. B. von Frese, Analysis of Magsat magnetic contrasts across Africa and South America, in Lithospheric Analysis of Magnetic and Related Geophysical Anomalies, edited by R. R. B. von Frese and P. T. Taylor, pp. 59-76, 1992.

Ravat, D. N., M. Pilkington, M. Purucker, T. Sabaka, P. T. Taylor, R. R. B. von Frese, and K. A. Whaler, Recent advances in the verication and geologic intgerpretation of satellite-altitude magnetic anomalies. 68th Annual Meeting, Society of Exploration Geophysicists, Expanded Abstracts, pp. 507-510, 1998.

Ravat, D. N., K. A. Whaler, M. Pilkington, T. J. Sabaka, and M. Purucker, Compatibility of high-altitude aeromagnetic and satellite-altitude magnetic anomalies over Canada, Geophysics, 67, 546-554, 2002.

Roeser, H. A., J. Fritsch, and K. Hinz, The development of the crust of Dronning Maud Land, East Antarctica, in Weddell Sea Tectonics and Gondwana Break-up, edited by B. C. Storey, E. C. King, and R. A. Rivermore, Volume 108, London: Geological Society, 1996.

Schandl, E. S., M. P. Gorton, and F. J. Wicks,. Mineralogy and geochemistry of alkali basalts from Maud Rise, Weddell Sea, Antarctica, Proceedings of the Ocean Drilling Program, Scientific Results, Part B (113), pp. 5-13, edited by Barker, P. and J. P. Kennett, 1990.

Smith, G. M., The magnetic structure of the marine basement, Rev. Aquat Sci., 2, 205-227, 1990.

Taylor, P. T. and J. Y. Frawley, Magsat anomaly data over the Kursk region, U.S.S.R., Phys. Earth Planet. Int., 45, 255-265, 1987.

Thomas, H. H., A model of ocean basin crustal magnetization appropriate for satellite elevation anomalies, J. Geophys. Res., 92, 11609-11613, 1987.

Toft, P. B. and J. Arkani-Hamed, Magnetization of the Pacific Ocean lithosphere deduced from Magsat data, J. Geophys. Res., 97, 4387-4406, 1992 
Toft, P. B. and J. Arkani-Hamed, Induced magnetization of the oceanic lithosphere and ocean-continent magnetization contrast inferred from Magsat anomalies, J. Geophys. Res., 98, 6267-82, 1993.

Tucholke, B. E., R. E. Houtz, and D. M. Barrett, Continental crust beneath the Agulhas Palteau, southwest Indian Ocean, J. Geophys. Res., 86, 3791-3804, 1981.

von Frese, R. R. B., Correction to: von Frese, R. R. B. and W. J. Hinze and L. W. Braile, "Spherical earth gravity and magnetic anomaly analysis by equivalent point source inversion" [Earth. Planet. Sci. Lett., 53, 69-83, 1981] Earth. Planet. Sci. Lett., 163, 409-411, 1998.

von Frese, R. R. B., W. J. Hinze, and L. W. Braile, Spherical earth gravity and magnetic anomaly analysis by equivalent point source inversion, Earth Planet. Sci. Lett., 53, 69-83, 1981a.

von Frese, R. R. B., W. J. Hinze, L. W. Braile, and A. J. Luca, SphericalEarth gravity and magnetic anomaly modeling by Gauss-Legendre quadrature integration, J. Geophys., 49, 234-242, 1981b.

von Frese, R. R. B., W. J. Hinze, R. Olivier, and C. R. Bentley, Regional magnetic anomaly constraints on continental breakup, Geology, 14, 6871, 1986.

von Frese, R. R. B., D. N. Ravat, W. J. Hinze, and C. A. McGue, Improved inversion of geopotential field anomalies for lithospheric investigations, Geophysics, 53, 375-385, 1988.

von Frese, R. R. B., L. Tan, J. W. Kim, and C. R. Bentley, Antarctic crustal modeling from the spectral correlation of free-air gravity anomalies with the terrain, J. Geophys. Res., 104, 25275-25297, 1999a.

von Frese, R. R. B., H. R. Kim, L. Tan, J. W. Kim, P. T. Taylor, M. E. Purucker, D. E. Alsdorf, and A. J. Anderson, Satellite magnetic anomalies of the Antarctic crust, Ann. di Geofisica, 42, 293-307, 1999b. von Frese, R. R. B., H. R. Kim, P. T. Taylor, and J. W. Kim, CHAMP, Ørsted, and Magsat magnetic anomalies of the Antarctic lithosphere, in First CHAMP Mission Results for Gravity, Magnetic and Atmospheric Studies, edited by C. Reigber, H. Lühr, and P. Schwintzer, pp. 309-314, Springer Verlag, Berlin, 2003.

von Frese, R. R. B., H. R. Kim, P. T. Taylor, and M. F. Asgharzadeh, Reliability of CHAMP anomaly continuations, in Earth Observation with CHAMP Results from Three Years in Orbit, edited by C. Reigber, H. Luhr, P. Schwintzer, and J. Wickert, pp. 287-292, Springer Verlag, Berlin, 2004.

Wasilewski, P. J. and M. A. Mayhew, The Moho as a magnetic boundary revisited, Geophys. Res. Lett., 19, 2259-2262, 1992.

Wasilewski, P. J., H. H. Thomas, and M. A. Mayhew, The Moho as a magnetic boundary, Geophys. Res. Lett., 6, 541-544, 1979.

H. R. Kim (e-mail: kimhr@core2.gsfc.nasa.gov), R. R. B. von Frese, A. V. Golynsky, P. T. Taylor, and J. W. Kim 